\title{
Logical analysis of the impact of supply chain relationship quality on the growth performance of start-ups
}

\author{
He JIANG ${ }^{1, a}$, Yonghui CAO 2, b* \\ ${ }^{1}$ Department of Business Administration, Guangzhou College of Technology and Business, Guangzhou, China \\ ${ }^{2}$ Department of Business Administration, Guangzhou College of Technology and Business, Guangzhou, China
}

\begin{abstract}
Due to the dilemma of "new entry defects" in the newly established enterprises, they are limited in developing new resources and cannot meet the increasingly fierce competition needs. Therefore, it is necessary to establish a stable strategic partnership by seeking external organizations, so as to obtain the necessary resources for the growth and development of the enterprise itself. Based on Penrose's theory of enterprise growth, this paper analyzes the relationship between the quality of supply chain relationship and the growth performance of start-ups from three aspects, in order to reveal the internal logic that the quality of supply chain relationship affects the growth performance of start-ups.
\end{abstract}

\section{INTRODUCTION}

Based on the background of mass entrepreneurship and innovation in China and the support of national policies, how to seize the development opportunities, improve the survival rate and competitive advantage of new enterprises is a very concerned issue in the theoretical and business circles. Looking back on the history of the growth and rise of Japanese enterprises, we can find some ideas and practices worthy of reference. In the 1980s, Japanese manufacturing enterprises began to attach importance to the cooperative relationship with suppliers, actively invest in the construction of production facilities of suppliers, and form the Keiretsu relationship of mutual trust and mutual benefit, namely the strategic partnership. Through the typical Keiretsu relationship, a linkage and cooperation mechanism between enterprises and members of the supply chain organization is formed to produce and sell standardized products with high and new technology, which has achieved great success in the market. Toyota company, which we are familiar with, is one of the outstanding enterprise representatives. Toyota uses the idea of supply chain relationship to manage suppliers effectively. It has formed a seamless integration platform between enterprises and suppliers, improved product and service quality, and become a model for American and European automobile manufacturers to learn from. For the current vigorous development of China's new enterprises, if we can combine the characteristics of their own resources, and according to the changes of the external environment, form a supply chain relationship quality that matches the environment, it will play a positive role in promoting the development of technological innovation and product market development of enterprises This is also a feasible way to realize the rapid growth of new enterprises[1-3].

The quality of supply chain relationship has important practical value for the growth of enterprises, which has been supported by scholars at home and abroad. Uzzi takes the New York clothing industry as an example to conduct an empirical study on the relationship quality of supply chain of related enterprises[4]. In the research, the relationship quality of supply chain is measured from three aspects: information sharing, trust and joint problem solving. The results show that the quality of relationship with supply chain members can positively affect the product innovation performance of enterprises. The reason is that a good supply chain partnership can better adapt to environmental changes than a simple contract transaction, can form positive interaction and market information sharing, enhance the accuracy of technological innovation, reduce the cost of product innovation, and thus improve corporate income. Narasimhan \& jayaram used structural model to test the impact of supply chain cooperation on product innovation performance[5]. The research points out that the supply chain cooperation is mainly reflected in three aspects: upstream organization, enterprise itself and downstream organization, that is, upstream supply material customization, enterprise's own production goal setting and downstream customer responsiveness. And as the three aspects of supply chain cooperation, the higher the degree, the better the promotion of new product performance. Fynes, Voss \& de B ü RCA studied the electronic enterprises in Ireland, and through the analysis of the survey data of 200 enterprises, found that the quality of supply chain relationship has a positive impact on the quality performance of new product design quality, production quality and customer satisfaction. Ram et al. pointed out that the close relationship with upstream and 
downstream enterprises in the supply chain can improve the quality of cooperation between the two sides, so as to promote the depth and efficiency of cooperation, and help to form the core competitiveness of enterprises. In the research, the author emphasizes that supply chain cooperation can reduce the opportunistic behavior in the transaction and facilitate the formation of a flexible mechanism of mutual trust. According to the technical requirements of partners, supply chain enterprises focus on the formation of high asset characteristic technology with unique value. It also outsources the non-core business of the enterprise, improves the technical competitiveness of the enterprise, responds to the service demand of the upstream and downstream partners, achieves the strategic purpose of supply chain cooperation, and brings good performance for the cooperative enterprise. Dutta \& Hora pointed out that enterprise supply chain alliance can promote enterprise performance in commercialization[6].

In addition, Chinese scholars have also actively carried out relevant research in this regard. They point out that the quality of supply chain relationship has a positive impact on the development of new products, and interpreted it from three aspects. First, it can reduce the cost of resource acquisition and transaction, so as to reduce the total cost of new product research and development and manufacturing, and increase corporate income. Good supply chain relationship quality improves the coordination level of enterprises, makes both parties or multi-party partners more adapt to various interaction activities in cooperation, reduces various consumption in transactions, enables cooperation activities to smoothly carry out process connection, provides complementary diversified information and knowledge for product innovation of enterprises, and improves the level of technological innovation and manufacturing efficiency. The second is to improve the consistency quality and design quality of new products. A good supply chain relationship can have positive interaction with suppliers and customers, and share the frontier technology development and market demand information with upstream and downstream partners, so that these suppliers and customers can participate in the design and development of products, and the knowledge and design concept from various aspects improve the design quality of products. In addition, with various forms of technical exchange and innovation cooperation, suppliers can understand the raw material requirements of manufacturers more clearly, and also understand the production process and process of manufacturers, so as to provide parts that meet the needs of enterprises, make the production of new products smoothly, and ensure the consistency and quality of products. Third, it can create the core competitiveness of enterprises. Through the effective management of supply chain relationship quality, enterprises can form unique key capabilities, thus forming technology or market complementarity with supply chain partners, improving their comparative advantages and meeting cooperation needs. These real business cases and experience summary enrich the research content in the field of new enterprises, and also provide some reference for the healthy growth of new enterprises and supply chain management practice in China.

\section{THEORETICAL ANALYSIS}

According to the literature review, combined with the relevant case studies, this study conducted a logical sorting, focusing on the research questions: how does the quality of supply chain relationship affect the growth performance of new enterprises? And the research object is defined as technology-based start-up enterprises. Existing research shows that there are significant differences between new start-ups and incumbent enterprises in the following three aspects: they often lack strategic resources, lack of social legitimacy and social relations, and relatively less formal social roles. Therefore, compared with the incumbent enterprises, the formation and maintenance of the relationship between the start-up enterprises and the supply chain partners contain greater uncertainty, which requires interdisciplinary theory and methods.

Due to the dilemma of "new entry defects" in new enterprises, they are limited in developing new resources and cannot meet the increasingly fierce competition needs. In this case, new enterprises need to seek external organizations to establish stable strategic partnership, so as to obtain necessary resources for their own growth and development [7]. Penrose believes that the diversified resources owned by enterprises are the basis of enterprise growth, points out that the enterprise growth mechanism should be analyzed in the framework of "enterprise resources - Enterprise Capability - enterprise growth", and believes that enterprises are the collection of productive resources in a specific management framework, and the process of their continuous growth is the process of effective management and allocation of resources. That is to say, the abundance of resources and the efficiency of allocation can determine the ability of an enterprise, and the ability of an enterprise can further affect the speed and mode of its growth. It should be noted that in the framework of enterprise growth analysis put forward by Penrose, the resources of an enterprise are limited to the resources owned by the enterprise itself, and the discussion on the resources acquired from the outside is ignored or not mentioned intentionally by the author. Some scholars regard supply chain relationship as an important resource of enterprises, and believe that highquality supply chain relationship can help to achieve the expected economic goals. These relationship qualities play a central role in the growth of enterprises. Therefore, based on the theory of supply chain relationship quality, this study, under the framework of Penrose's enterprise growth analysis, combined with exploratory cases, explores the types of key capabilities needed for enterprise growth. This paper uses Drucker's judgment on the basic functions of enterprises (innovation and marketing) for reference, comprehensively uses the theories of enterprise growth, dynamic capability and value realization, analyzes the black box of the role of supply chain relationship quality and growth performance of new enterprises, and reinterprets the analysis 
framework of enterprise growth mechanism put forward by Penrose.

In addition, the relationship between supply chain node enterprises is constantly changing. The change of any variable related to the relationship (whether external or endogenous) will inevitably lead to the change of relationship quality. Arino \& de la Torre écalled for a phased understanding of the evolution of supply chain relationship quality. However, Greiner's theory of enterprise life cycle, Helfat \& petersaf's theory of capability life cycle and Batonda \& Perry's and Kam \& Lai's research provide a reference for the quality evolution of supply chain relationship in the growth stage of new enterprises[8]. Therefore, through the study of the above issues, the internal mechanism of the impact of supply chain relationship quality on the growth performance of new start-ups is systematically analyzed, so as to provide theoretical support and practical guidance for the sustainable development of new start-ups.

\section{MODEL CONSTRUCTION AND ANALYSIS}

This paper focuses on the framework of "the influence mechanism of supply chain relationship quality on the growth performance of new ventures", combined with literature review and exploratory cases, and intends to make a scientific analysis of the relationship between the two from three aspects. Among them, sub study 1 is the analysis of the basic influence and regulatory effect of supply chain relationship quality on the growth performance of new start-ups; Sub study 2 is the analysis of the internal influence mechanism of the relationship quality of supply chain on the growth performance of start-ups; Sub study 3 is the dynamic evolution effect of supply chain relationship quality on the growth performance of start-ups. The specific analysis is as follows:

\subsection{The impact of supply chain relationship quality on the growth performance of new start- ups: moderating effect}

Research ideas: it mainly analyzes the relationship between the quality of supply chain relationship and growth performance, and further clarifies the existing divergent conclusions; On this basis, strategic orientation (innovation orientation and market orientation) is introduced to analyze the relationship between the two. This is a situational study on the impact of supply chain relationship quality on the growth performance of new ventures, that is, to explore the regulatory mechanism between the two.

Research content: the research object is limited to science and technology-based start-ups. The controlling factors are: the nature of the enterprise, the period of establishment and the scale of the enterprise. In the analysis of its regulating mechanism, the influencing factors are the quality of supply chain relationship, the regulating factors are innovation oriented and marketoriented, and the influencing results are enterprise growth performance (innovation growth performance and market growth performance). In the context of innovation oriented and market-oriented, this paper analyzes how the quality of supply chain relationship affects the growth performance of new enterprises.

\subsection{Sub study 2, the impact of supply chain relationship quality on the growth performance of new start-ups: a moderating intermediary}

Research ideas: Based on case analysis and literature review, and on the basis of sub study 1, this paper mainly studies the intermediary mechanism of the impact of supply chain relationship quality on growth performance. Based on Penrose's analysis framework of enterprise growth mechanism (enterprise resource enterprise capability enterprise growth), resource-based theory and Drucker's judgment on the basic functions of enterprises, and drawing on the theory of value creation and value transfer, this paper makes a detailed analysis on the intermediary variables of supply chain relationship quality and growth performance of new enterprises. Furthermore, the paper analyzes the management black box that the relationship quality of supply chain affects the growth performance of new enterprises.

Research content: the research object is limited to science and technology-based start-ups, and the control factors are: the nature of the enterprise, the establishment period and the scale of the enterprise. In the analysis of its internal mechanism, the influencing factor is the relationship quality of supply chain. The intermediary factors are knowledge reconstruction ability and marketing integration ability. The result is the growth performance (including innovation growth performance and market growth performance). The framework of this study follows the classic IPO model. In the framework of Penrose's enterprise growth mechanism, this paper analyzes how supply chain relationship quality affects the growth performance of new enterprises through knowledge reconstruction ability and marketing integration ability. The interaction between environmental dynamics and the quality of supply chain relationship is analyzed in detail, and how the intermediary factors affect the growth performance of new enterprises is analyzed.

\subsection{Sub study 3: the impact of supply chain relationship quality on the growth performance of new start-ups: evolutionary mechanism}

Research ideas: Based on the study of 1 and 2, from the perspective of evolutionary theory, this study analyzes the impact mechanism of supply chain relationship quality on the growth performance of new enterprises based on vertical cases. In the research, we use the theory of enterprise life cycle and capability life cycle for reference, and explore the dynamic change law of the relationship quality of supply chain of new enterprises. The core development of supply chain relationship quality and its influencing factors are analyzed in detail. It also reveals the dynamic evolution mechanism of the relationship quality of supply chain for the growth performance of new enterprises in each development stage. It makes up 
for the lack of previous studies that seldom consider the impact of supply chain relationship quality on the growth and change of new start-ups from a dynamic perspective.

Research content: Based on the theory of environmental uncertainty, resource endowment and strategic matching, and from the perspective of dynamic evolution, this paper analyzes the factors and laws that affect the quality change of supply chain relationship according to each different stage in the development process of new enterprises. This part systematically analyzes the evolution of the relationship quality of supply chain from the start-up stage, the growth stage to the improvement stage and its impact on the growth performance of new enterprises. The purpose of this paper is to explore the dynamic evolution mechanism between the two, to provide appropriate theoretical support and practical suggestions for each stage of the growth of new enterprises, so that new enterprises can build appropriate supply chain relationship quality according to the dynamic changes of their own development stage, so as to promote sustainable growth.

In a word, according to the analysis, this paper takes the technology-based start-ups as the research object, and follows Penrose's analysis framework of enterprise growth mechanism as the theoretical basis. Combined with supply chain relationship quality theory, resourcebased theory, dynamic capability theory, enterprise life cycle theory, dynamic evolution theory, situation theory and so on, the overall research framework of this paper can be constructed as clearly as possible, so as to comprehensively and deeply explore the mechanism of supply chain relationship quality affecting the growth of new enterprises.

\section{LOGICAL RELATIONSHIP BETWEEN SUB STUDIES}

According to the analysis, this paper is mainly divided into three sub studies. The three sub studies have internal logical relations as shown in Figure 1:

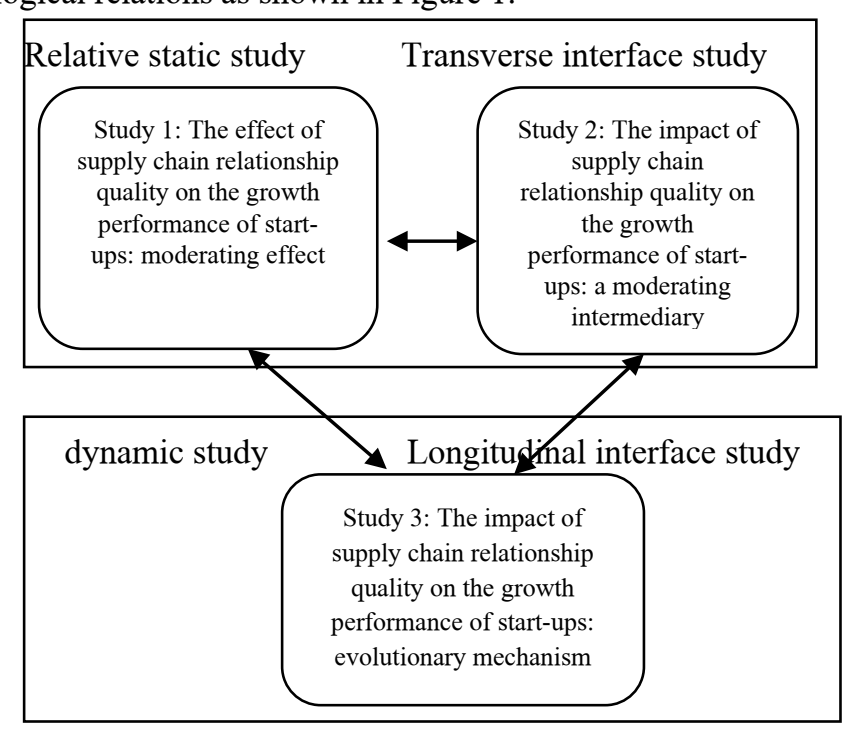

Figure 1. Logic diagram of three sub studies
Note: the two-way arrow indicates that there is a relationship between the studies

The first sub study is to clarify the relationship between supply chain relationship quality and growth performance. This part analyzes how the quality of supply chain relationship affects the growth performance of new enterprises in the context of innovation orientation and market orientation. Research 2 is based on Penrose's analysis framework of enterprise growth mechanism and Drucker's basic function judgment. Combined with the theory of dynamic capability, value realization and enterprise relationship view, this paper explores the internal mechanism of the relationship quality of the supply chain of the newly established enterprises affecting the growth performance of the enterprises. Research 3 is from the perspective of evolution theory, analyzing the evolution and development process of supply chain relationship quality and its impact on growth performance. It is an exploration based on sub research 1 and sub research 2, and it is also an important supplement and improvement to research 1 and research 2 .

In general, the three studies in this paper are independent and interrelated. Research 1 and research 2 belong to the static horizontal research (Note: Although the knowledge reconstruction ability and marketing integration ability in the research belong to the dynamic ability category, the overall research is still dominated by static analysis, so this paper will attribute research 1 and research 2 to the static research category). Study 3 is a dynamic longitudinal interface study. The three studies constitute a complete logical framework and research paradigm of the impact of supply chain relationship quality on the growth performance of new start-ups, which can deeply analyze its internal mechanism and provide theoretical and practical reference for new startups.

\section{CONCLUSIONS}

Based on the practical background and literature review, this study puts forward research questions, and uses the results of case study for reference to explore the construction of the research model, constructs a theoretical model of the impact of supply chain relationship quality on the growth performance of startups, and makes a logical analysis between the sub studies. This paper has positive reference and theoretical value for the improvement of the growth performance of new enterprises, which can be tested by empirical research in the future.

\section{ACKNOWLEDGMENT}

This work is financially supported by Guangdong Education Science Planning Project, building an efficient and intelligent supply chain system to promote the highquality economic development of Guangdong-Hong Kong-Macao Greater Bay Area, 2019GXJK072; outstanding scholars of philosophy and Social Sciences in Henan Province higher education in 2018, 2018-YXXZ06; Henan philosophy and Social Sciences Planning 
Project in 2019, 2019BJJ003; The social development project of Henan provincial key R \& D and promotion project (Science and technology tackling key problems) in 2019, project number: 515; Henan philosophy and Social Sciences Planning Project in 2019, 2019BJJ032; General Topics of Henan Province Educational Science "13th Five-Year Plan" in 2020, 2020YB0146; the key scientific research project of colleges and universities in Henan Province in 2021, 21A620002; Foshan social science planning project in 2020, 2020-QN11; Intellectual property soft science research project of Henan Province in 2021, 20210106014. Thanks for the help.

\section{REFERENCES}

[1] Tsai, J. M., \& Hung, S. W. Supply chain relationship quality and performance in technological turbulence: an artificial neural network approach. International Journal of Production Research, 2016, 54(9), 27572770.

[2] Abosag, I., Yen, D. A., \& Barnes, B. R. What is dark about the dark-side of business relationships. Industrial Marketing Management, 2016(55), 5-9.

[3] Ndubisi, N. O. Conflict handling, trust and commitment in outsourcing relationship: A Chinese and Indian study. Industrial Marketing Management, 2011, 40(1), 109-117.

[4] Uzzi, B, Lancaster R. Relational embeddedness and learning: The case of bank loan managers and their clients. Management science, 2003, 49(4), 383-399.

[5] Narasimhan, O., Rajiv, S., \& Dutta, S. Absorptive capacity in high-technology markets: The competitive advantage of the haves. Marketing Science, 2006, 25(5), 510-524.

[6] Dutta, D. K., \& Hora, M. From Invention Success to Commercialization Success: Technology Ventures and the Benefits of Upstream and Downstream Supply - Chain Alliances. Journal of Small Business Management, 2017, 55(2), 216-235.

[7] Villena, V. H., Revilla, E., \& Choi, T. Y. The dark side of buyer-supplier relationships: A social capital perspective. Journal of Operations management, 2011, 29(6), 561-576.

[8] Kam, B. H., \& Lai, M. K. Buyer-supplier exchange relationship: How do exchange partners behave across the relationship life-cycle?. Transportation Research Part E: Logistics and Transportation Review, 2018, 113, 239-257. 